\title{
A 9 YEAR ANALYSIS OF DROWNING IN CHILDREN AND ADOLESCENTS AGED 5-19 YEARS IN AUSTRALIA, 2002-2011
}

doi:10.1136/injuryprev-2012-040590h.7

A Peden. Royal Life Saving Society—Australia

Background There has been limited analysis and exploration of drowning deaths that occur in children aged 5-19 years.

Aims/Objectives/Purpose To undertake an analysis of drowning deaths of children 5-19 years in Australia.

To explore strategies for prevention.

Methods Information was collected for the period July 2002 to June 2011 on all drowning deaths in Australia using multiple sources including the National Coroners Information System. Cases were excluded if he death was intentional (ie suicide, homicide), from natural causes, or from an animal (eg shark attack, crocodile attack), or hypothermia where known.

Results/Outcome Over the 9 years there were 271 (46\%) deaths of 5-19-year-olds. As children aged, the predominant locations of drowning deaths transitioned from home environments (swimming pools and bathtubs) to open waterways (rivers, creeks and streams). A related transition occurred in activity prior to drowning, where younger children were more likely to fall into water and be bathing and older children drowning in more active pursuits such as swimming and recreating, using watercraft and intentionally entering the water. Gender plays a key role, with $87 \%$ of all drowning victims being male in the 15-19 years age group. As adulthood approaches the number of deaths increase.

Significance/Contribution to the Field Drowning in children aged 5 to 19 years is a significant issue that has been largely neglected in Australia. Royal Life Saving believes that these drowning deaths are preventable and that the increase in drowning deaths in late adolescents points to the importance of swimming and water safety education during the school years. 